\title{
Gaming or gambling?
}

The scientific community needs to engage actively in the debate regarding the status of video game loot boxes and the potential risks they present for vulnerable populations.

W hen a beta version of Star Wars Battlefront II was released last October, it caused immediate and unprecedented uproar in the gaming community: game progression relied to a large extent on in-game purchases of randomized rewards - or loot boxes. Legislators and regulators soon took notice and engaged. On 22 November 2017, Hawaii State Representative Chris Lee decried the game as "a Star Wars-themed online casino designed to lure kids into spending money" (https://go.nature.com/2xj58JA). At the same time, the Belgian Gaming Commission opened an investigation into this and similar games to determine whether their loot-box systems qualified as gambling according to Belgian law.

After unrelenting criticism, the game's developer, Electronic Arts, removed the option of purchasing loot boxes with real money in the official release of the game (https://www.cnbc.com/2018/03/16/ ea-vows-to-never-offer-paid-loot-boxes-inits-controversial-star-wars-battlefront-iigame.html). However, Star Wars Battlefront II isn't the only game giving players the option to buy randomized rewards that offer competitive advantage. And the debate in the public sphere as to whether video games that include loot boxes purchasable for real money constitute a form of gambling is still raging. Because a significant proportion of video gamers worldwide are children and adolescents - for instance, more than $90 \%$ of US children and adolescents aged 2-17 play video games (https://go.nature. com/2GXagm4) - the debate has acquired particular urgency.

In a Comment in this issue, Drummond and Sauer conclude that the loot boxes contained in several recently released games rated as appropriate for underage players fit the definition of gambling: they are purchasable for real money, they are received only after payment, their contents are randomly determined, losses can be averted by choosing not to buy them and winners profit at the expense of losers by gaining direct competitive advantage. In some of the games, players can also cash out their winnings, by selling the items received from the loot box through thirdparty sites or the platform through which the game is distributed. Importantly, a

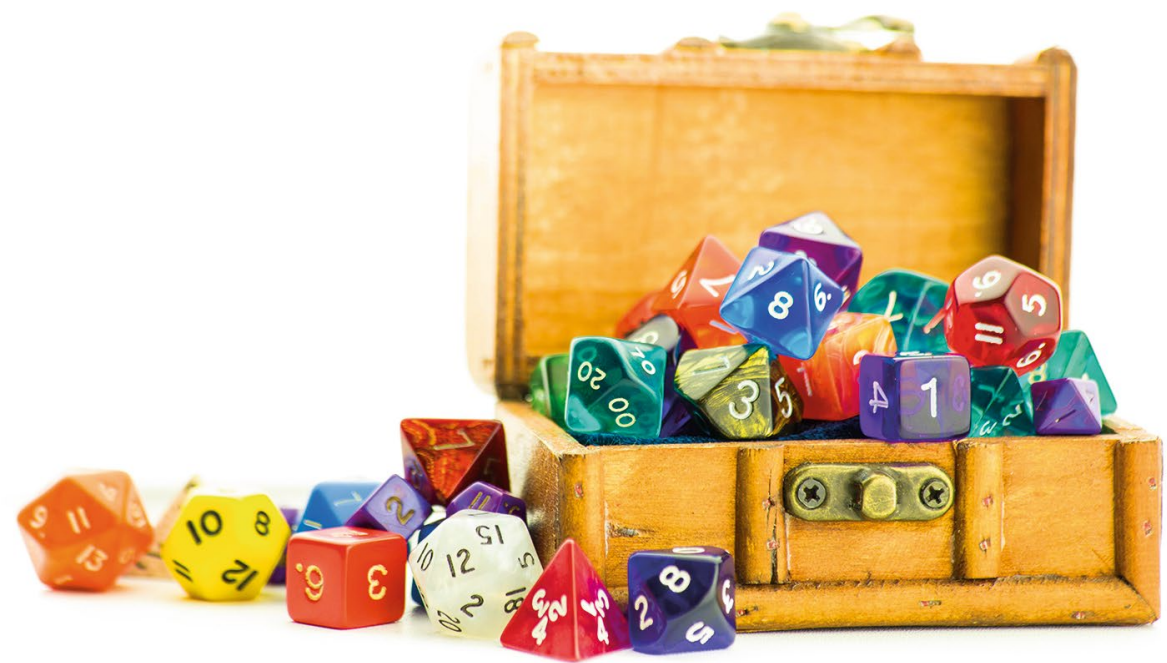

Credit: Rowan Jackson / Alamy Stock Photo

number of these games were rated by the Entertainment Software Ratings Board (ESRB) as appropriate for audiences aged 13 or younger.

In April 2018, the Belgian Gaming Commission published its report on the paid loot boxes contained in four games (Overwatch, FIFA 18, Counter-Strike: Global Offensive and Star Wars Battlefront $I I)$, concluding that they all constituted gambling, contravened Belgian law and should be removed (that had already happened for Star Wars Battlefront II by the time the report was published; https://go.nature.com/2IT8wvQ). The Netherlands Gaming Authority reached similar conclusions based on Dutch law for four out of ten unnamed loot-boxcontaining games it investigated (https:// go.nature.com/2kw8qzG). Belgium and the Netherlands join a handful of other countries already regulating loot boxes in video games, such as China, Japan and Australia. However, influential selfregulating bodies providing rating systems for video game content, such as the ESRB and Pan European Game Information (PEGI), have not moved to regulate such content. ESRB president Patricia Vance said in February 2018, "We think [loot boxes are] a fun way to acquire virtual items for use within the game, to personalize your experience." She added that the ESRB has been "unable to find any evidence that children specifically have been impacted by loot boxes or leading them to some sort of tendency towards gambling. We really truly don't know of any evidence supporting those claims" (https://go.nature.com/2IUClwe).

With more than two billion gamers worldwide, the digital gaming industry yielded revenues of more than US $\$ 90$ billion in 2017. In-game purchases are a recent means used by the industry to monetize its products, and loot boxes are one example. Whether paid loot boxes fit the legal definition of gambling depends on the legal framework of each country. Regardless of legal status, however, the scientific community needs to take on an active role in this issue: by raising awareness of known behavioural and psychological impacts of the reward structures employed in loot boxes, by specifically investigating the impacts of different types of lootbox incarnations in video games, and by working with legislators and regulators to ensure that appropriate protections are put in place for minors and other vulnerable populations.

Published online: 7 August 2018 https://doi.org/10.1038/s41562-018-0369-5 